\title{
Visual Perception in Architecture and Cinema, Similarities and Differences
}

\author{
Hassan Ebrahimi Asl and Parinaz Mizban
}

\begin{abstract}
Architecture and cinema, the first one is a kind of art related to beginning of life and human being in this globe and the latter is the product of modern era and 20th century in addition they are the significant branches of art that virtual communication plays an important role on them in perception and transmission concepts and contents. Acquaintance with dimensions of this communication lead to exploring new ways in coherence between these two fields.

Due to lack of time and turning human's perception into virtual in nowadays life, this study can be useful in facilitating connection between human and his environment. Our aim in this paper, first is exploring and clarifying visual communication in every field then finding the common factors which can be transmit between these two fields. At the end we reach this point that architecture and cinema have much in common in terms of visual perception and transmission, expanding this connection can lead to preparing new thoughts, ideas and new methods in visual communications. Consolidating these two majors in terms of visual communications can start new areas in this field.
\end{abstract}

Index Terms-Visual components, perception, architecture, cinema, similarities, differences.

\section{INTRODUCTION}

'A picture is worth a thousand words.' This popular faux-Chinese proverb could be the first sentence in a credo of visual programming research. Nowadays visual literacy has become an important and accepted term for the ability to comprehend pictures, other visual messages and communications, furthermore there is a great interest in propelling human perception toward visual messages. Maybe cinema in contradistinction with architecture is more visual, in other words it applies visual components more than architecture in transmitting concepts and contents but at this time due to lack of time and human patience in getting signals, concepts and contents of the built environment, visual transmission becomes prominent component in architecture. It seems that cinema as a kind of art which is somehow successful in visual communications and most related to architecture, has more in common with it and therefor some of its prominent components in visual communication can be borrowed and utilized in architecture.

For the sake of completeness, in this review first we briefly recap the process of vision and then concentrate on visual components in cinema and architecture and finally we focus

Manuscript received January 22, 2015; revised April 28, 2015.

Hassan Ebrahimi Asl is with Department of Architecture Management, College of Architecture, Najafabad Branch, Islamic Azad University, Najafabad, Iran (e-mail: Hassan.ebrahimy@gmail.com).

Parinaz Mizban is with Department of Architecture Management, Hadishahr Branch, Islamic Azad university, Hadishahr, Iran (email:p_mizban@yahoo.com) on similarities and differences. This review will be relatively brief and, of necessity, incomplete. We hope to give an overview of the different research areas concerned with visual perception in architecture and cinema.

\section{VISION}

In order to understand the working of eyes, first it will be better to understand the physical properties of light, and the biochemistry of its absorption by photoreceptors.

Light can be thought of as lots of little balls (photons, to give them their proper name) that arrive from the sun, or a light bulb, or some other source. These balls bounce off the objects around us, the trees, cars, humans, and so on, and some of them just happen to bounce in such a way that their path takes them from the object and through a tiny transparent window in our eye. Inside our eyes, these balls are collected and vision begins (Fig. 1). By way of analogy, we could imagine a little man with a net catching these light balls and, from the contents of his net, doing all the things that vision does-seeing colors, knowing that a car is coming toward him, recognizing that his friend has a new haircut, reaching out and picking up his coffee cup ... and a million other thing. Put like this, vision appears bewilderingly difficult [1].

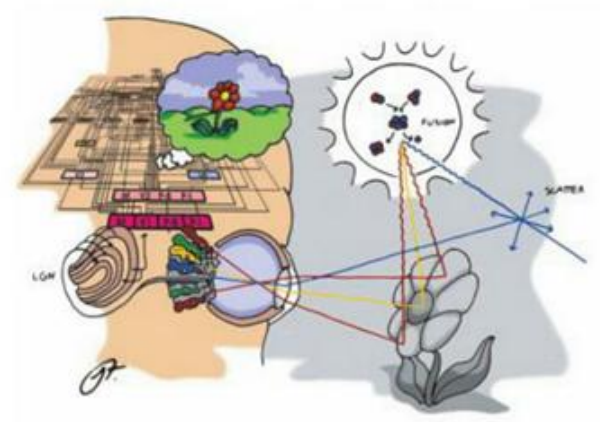

Fig. 1. Process of seeing object (Robert Snowden and others).

\section{MATH}

So, vision isn't here to form a pretty picture of the world, it's there in order for us to be able to make sense of what is out there and so interact with it, and to actively seek information about the world. If you carefully watch a person as they perform any visual task, from merely watching TV to driving a car at high speed, you will see that their eyes do not merely stand still and absorb information; instead, they flick rapidly from place to place, in almost constant motion.

If we measure eye movements carefully, we find that the eyes move about 3-4 times per second as we perform these 
tasks. Our central vision gives us really good detail of the point we are looking at. However, as we move further and further away from this point our vision gets worse and worse. Thus, at any one moment we only have really sharp vision for one small part of the world and in order to understand what is going on we need to move our eyes around. Our visual system is not there to faithfully record the image outside, it is there to give us necessary information for us to behave appropriately [1] (see Fig. 2).

So the point is, our perception in real environments and architecture is pretty one-way and we can focus and get details merely in specific domain which in comparison with perception in virtual environments and cinema we can claim that perception in cinema is wider and clearer than perception in built environment and architecture.

\section{PERCEPTION PROCESS}

The physical experience of watching a film may outwardly appear to be a very passive activity. However, the viewer is highly active. The viewer must process the rapid sequence of audiovisual information, perceive what is represented on the screen, comprehend the characters, spaces and actions depicted and engage in the construction of the narrative throughout the film. The only external evidence of this internal activity visible to an observer are facial expressions, bodily movements, physiological changes (e.g. heart rate, sweating, and pupil dilation), involuntary vocalizations (e.g. laughter, screams), and eye movements. Every eye movement indicates a new phase of visual processing.

Due to visual acuity limitations of the human eye we cannot see the whole visual scene in detail at the same time and must move our eyes to sequentially process the parts of the scene we are interested in. Retina, the light-sensitive layer at the back of the eye, is the important bit and the start of real visual processing [2].
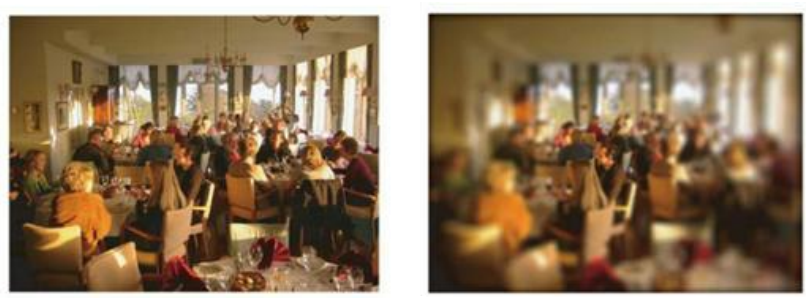

Fig. 2. Acuity decreases with eccentricity ((Robert Snowden and others).

It can only process high-resolution color information at its very center due to the distribution of photoreceptive cells. There are two types of photoreceptor in the retina: rods, that are sensitive to light at low light levels; and cones, that are sensitive to color and light at normal light levels. The rods and cones are unevenly distributed across the retina with the periphery predominantly covered by rods and most of the cones concentrated in a small region at the center of the retina called the fovea. This region only occupies about 2 degrees of a visual angle, roughly equivalent to the portion of the scene covered by a thumbnail held at arm's length. The resolution of the image we perceive is greatest when processed by cones so drops rapidly as the distance from the fovea increases. Five degrees away from the fovea resolution drops by $70 \%$ and by 20 degrees it has dropped by $90 \%$ (where $360^{\circ}$ is a circle horizontally encircling the viewer's head). As a result, we only have access to high resolution color information about the part of the scene projected on to or close to the fovea [3] (see Fig. 3).

When our eyes stabilize on a point in space (i.e. fixate), encoding of visual information occurs. Each fixation lasts on average $330 \mathrm{~ms}$ [4]. It varies in duration with the complexity of visual stimuli and viewing task. To process a new part of the scene the eyes must rotate so that the new target is projected on to the fovea. These rapid eye movements are known as saccades and have a duration of 20-50ms and cover a distance of about $4^{\circ}$. If the target of our attention requires a large saccade $\left(>30^{\circ}\right)$ or is outside of our current field of view $\left(120^{\circ}\right)$ the eye movement will be accompanied by a head and/or body rotation. When sat in a movie theatre, the angle occupied by the screen is likely to be greater than $30^{\circ}$ as the recommended minimum viewing angle for the back row of a cinema auditorium is $35^{\circ}$ and the closer a viewer sits to the screen the larger the viewing angle from one side of the screen to the other will be. For the majority of the audience members the screen will subtend a significantly larger viewing angle necessitating a head rotation along with saccadic eye movement to comfortably view the edges of the screen [3].

The sequence of fixations and saccades creates a scanpath: a record of where the viewer's eyes were pointed during a viewing period, which elements of the scene they were most likely to have attended, perceived, encoded in memory and, also the parts of the scene that were not attended.

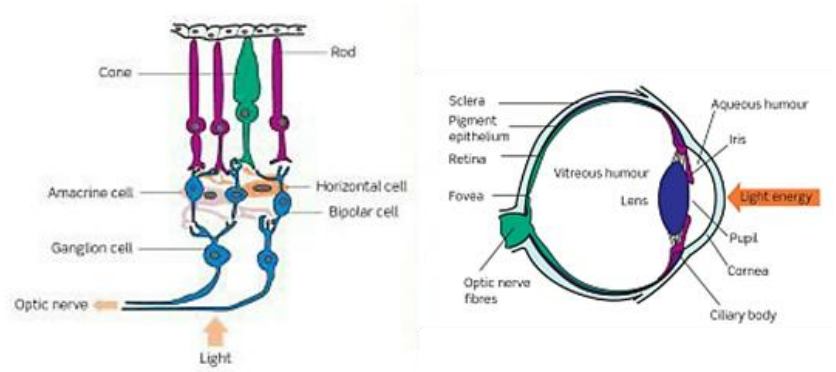

Fig. 3. Cross section through the human eye and retina (Robert Snowden and others).

\section{VISUAL COMPONENTS IN CINEMA}

The basic visual components are space, line, shape, tone, color, movement, and rhythm. These are our cast of characters, although we may be more familiar with the other cast called actors, both casts are critical to producing great work [5].

1) Space: this is not outer space or "giving someone his or her space". There are three kinds of visual space: first, the physical space in front of the camera; second, the space as it appears on screen; and third, the special size and shape of the screen itself.

2) Line and shape: line is a perceptual fact. It exists only in our heads. Line is the result of other visual components that allow us to perceive lines, but none of the lines we see is real. Shapes goes hand in hand with line, because all shapes appear to be constructed from lines. 
3) Tone: tone refers to the brightness of objects in relation to the gray scale. Tone does not refer to the tone of scene (sarcastic, excited, etc.), or to audio tone (treble and boss). Tone is an important factor in black and white and color photography.

TABLE I: VISUAL COMPONENTS IN ARCHITECTURE AND CINEMA

\begin{tabular}{|c|c|c|}
\hline & Architecture & Cinema \\
\hline Line & $\begin{array}{l}\text { http://www.flashpacklife.com. Accessed January 13, } \\
\text { 2015. } \\
\text { usage of lines in Libeskinds architecture which is the } \\
\text { symbols of deconstruction and machine of his } \\
\text { architecture }\end{array}$ & $\begin{array}{l}\text { http://www.celluloidwickerman.com. Accessed } \\
\text { January 13, 2015. } \\
\text { In the movie of winter sleep by Bilge Jeylan, in } \\
\text { several shots we see the lines of railways which are } \\
\text { the symbols of modern and traditional turkey. And } \\
\text { they will never cut each other. }\end{array}$ \\
\hline Color & $\begin{array}{l}\text { http://www.irando.blogfa.com. Accessed January 13, } \\
\text { 2015. } \\
\text { Using red color by Bernard Tschomi in Parc de la } \\
\text { Villette r } \\
\text { For illustrating deconstruction symbols }\end{array}$ & $\begin{array}{l}\text { http://www.theguardian.com. Accessed January 13, } \\
\text { 2015. } \\
\text { Using red color by Steven Spielberg in Schindler's } \\
\text { List for attracting audience attention }\end{array}$ \\
\hline Tone & $\begin{array}{l}\text { http://www.arhiprofesor.wordpress.com. Accessed } \\
\text { January 13, 2015. } \\
\text { Using tone by Tadao Ando in church of the light }\end{array}$ & $\begin{array}{l}\text { 2015. } \\
\text { Using tone in the movie Manhattan by woody Allen } \\
\text { for highlighting the characters }\end{array}$ \\
\hline Rhythm & $\begin{array}{l}\text { http://www.myweb.wit.edu. Accessed January 13, } \\
\text { 2015. } \\
\text { In Vann Molyvann's designs in general, they always } \\
\text { consist such strong rhythm }\end{array}$ & $\begin{array}{l}\text { http://www.got-blogger.com. Accessed January 13, } \\
\text { 2015. } \\
\text { Rhythm is one of the prominent components of } \\
\text { cinema in visual transmitting }\end{array}$ \\
\hline
\end{tabular}

4) Color: one of the most powerful components is color.

5) Movement: movement is the first visual component to attract the eye. Movement occurs using objects, the camera and the viewer's eyes as they watch the screen.
6) Rhythm: we are most familiar with rhythm we can hear but there is also rhythm we can see. Rhythm is found in stationary objects, moving objects, and editing.

Visual perception and communication between audience 
and narrative can occur with these components in addition we can indicate and transmit concepts like love, fear, murder, danger, safety, peace, and etc. with them to audience. For instance, Steven Spielberg's Schindler's List (1993) uses black and white cinematography to tell the story of one man's attempts to save Jews from the concentration camps in Nazi occupied Poland. In one striking scene, Spielberg picks out a small girl in the chaos of Krakow's ghetto by depicting her red coat in full color against the monochrome background. In a later scene we catch a glimpse of the girl's coat amongst a pile of dead bodies. A poignant use of color to single out a character amongst the faceless mass of lost souls. The contrast of the coat against the grey background is striking and probably results in quicker gaze to the girl than would have occurred without the red coat.

Where we fixate in a visual scene is a consequence of the interaction between our internal plans, desires, and viewing tasks (known as endogenous control as it originates internally) and features of the audiovisual scene such as luminance, color, edges and motion (known as exogenous control as it originates externally). In cinema, the Audio features of a scene can also influence visual attention and where we fixate. In film, the inclusion of diegetic sounds, dialogue, off-screen sounds, and non-diegetic sounds such as soundtrack or narration may influence how viewers attend to the film [3]. Bordwell \& Thompson specified critical components in attracting audience attention, they mentioned: Most basically, our visual system is attuned to perceiving change, both in time and space. Our eyes and brains are better suited for noticing differences than for concentrating on uniform, prolonged stimuli. Thus aspects of mise-en-scene will attract our attention by means of changes in light, shape, movement, and other aspects of the image [6].

This influence of basic visual features via a film's mise-en-scène has also been noted by Bruce Block (2001). 'He believes that viewer's eyes will be primarily attracted by movement, then by bright points on the screen and by faces [7].'

\section{Visual COMPONENTS IN ARCHITECTURE AND CinemA}

Basic elements which have been discussed in visual components are somehow connected to architecture too. Space as a surrounded environment around us, shape, line, tone, color, movement and rhythm all are the basic visual components that have been applied in architecture for transmitting concepts for years. Among these components, movement is the only element that we can claim is more cinematic and there is another component which is more applying in architecture than cinema and it is texture. If we consider the texture as the element which we should touch it in order to cognize, we can conclude that it is more intelligible in architecture in contradistinction with cinema. In the below table we bring examples which illustrates the usage of same visual components in both architecture and cinema.

As mentioned, movement is one of other prominent visual components in cinema which plays an important role in films mis-en-scène. It can attract audience attention more easily than other visual components. Applying this component in architecture can open new modes of perception which mostly are increasing in a progressive way in city scales while it can be applied in architecture spaces in small scales for attracting and focusing the person's attentions too. Adding audio to architecture spaces can bring new steps in space perception and sense of place.(see Table I).

\section{CONCLUSION}

In this paper, first we briefly recapped the process of vision then we focused on visual components in architecture and cinema. Finally the points we have abstracted through comparing the visual process and components are:

1) Our perception in real environments and architecture is pretty one-way and we can focus and get details merely in specific domain which in comparison with perception in virtual environments and cinema we can acclaim that perception in cinema is wider and clearer than perception in built environment and architecture.

2) Space, line, shape, tone, color, movement, rhythm and texture are the basic visual components that are being applied in cinema in transmitting concepts and contents

3) Architecture has much in common with cinema in visual components except movement that is more cinematic and texture which is more related to architecture.

4) Motion is one of the basic elements of visual perception in cinema which it can be used also in architecture in order to attract audience's attention quickly.

5) Audio is one of another components in cinema that can also influence visual attention and can be applied in architecture too.

6) Our eyes and brains are better suited for noticing differences so changes in time, space, light, shape and movement will attract our attention

On the whole we can claim that architecture and cinema have much in commons in terms of visual perception and expanding this connection can develop new areas in this field and surely this review will be relatively brief and, of necessity, incomplete. We hope to give an overview of the different research areas concerned with visual perception in architecture and cinema.

\section{ACKNOWLEDGMENT}

Hassan Ebrahimi Asl thanks Dr. Armin Bahramian for his comprehensive and useful guides.

\section{REFERENCES}

[1] R. Snowden, P. Thompson, and T. Troscianko, Basic Vision, An Introduction to Visual Perception, revised ed., United Kingdom: Oxford, 2012, pp. 2-5.

[2] R. Snowden, P. Thompson, and T. Troscianko, Basic Vision, An Introduction to Visual Perception, revised ed., United Kingdom: Oxford, 2012, ch. 1, pp. 28.

[3] T. J. Smith, Watching You Watch Movies: Using Eye Tracking to Inform Cognitive film Theory, New York: Oxford University Press 2013, pp. 6-12.

[4] K. Rayner, "Eye movements in reading and information processing: 20 years of research," Psychological Bulletin, vol. 124, pp. 372-422, November 1998.

[5] B. Block, The Visual Story, Creating the Visual Structure of Film, TV and Digital Media, $2^{\text {nd }}$ ed., United Kingdom: Focal Press, 2013. ch. 1, pp. 2. 
[6] D. Bordwell, K. Thompson, and J. Ashton, Film Art: An Introduction, New York: McGraw-Hill, 1997, p. 189.

[7] B. Block, The Visual Story: Seeing Structure of Film, TV, and New Media, New York: Focal Press, vol.56, p. 132, 2001.

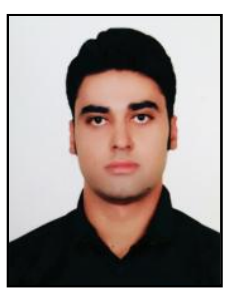

Hassan Ebrahimi Asl was born in Tabriz, Iran in 1987. He graduated from M.A course in architecture from the Islamic Azad University of Tabriz at 2013 and studying PhD from the Islamic Azad university of Najafabad in 2013. He has specialized and studying in the field of relation between cinema and architecture.

Hassan started teaching in the Islamic Azad University of Tabriz, Ahar and Jolfa from 2013 and was known as the youngest teacher in the university and $\mathrm{PhD}$ student.

Dr. Hassan Ebrahimi Asl is a member of Scientific Association of Architecture, Tabriz Branch and has lots of awards in architecture designing competitions.

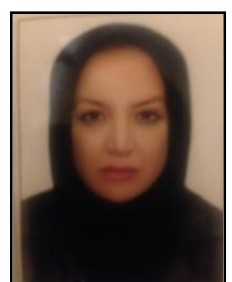

Parinaz Mizban Lighvan was born in Tabriz, Iran in 1974. She graduated from M.A course in architecture from the Islamic Azad University of Tabriz in 2005 and studying PhD from the Art University of Tehran in 2013. she has specialized and studying in the field of relation between place attachment and affordance on the basis of Phenomenology.

Parinaz started teaching in the Islamic Azad University of Tabriz, Hadishahr and Jolfa from 2008.

Dr. Parinaz Mizban Lighvan is a member of Scientific Association of Architecture, Tabriz Branch and has lots of awards in architecture designing competitions. 